\title{
Perspective
}

\section{Coupling the Biophysical and Social Dimensions of Wildfire Risk to Improve Wildfire Mitigation Planning}

\author{
Alan A. Ager, ${ }^{1, *}$ Jeffrey D. Kline, ${ }^{2}$ and A. Paige Fischer ${ }^{3}$
}

\begin{abstract}
We describe recent advances in biophysical and social aspects of risk and their potential combined contribution to improve mitigation planning on fire-prone landscapes. The methods and tools provide an improved method for defining the spatial extent of wildfire risk to communities compared to current planning processes. They also propose an expanded role for social science to improve understanding of community-wide risk perceptions and to predict property owners' capacities and willingness to mitigate risk by treating hazardous fuels and reducing the susceptibility of dwellings. In particular, we identify spatial scale mismatches in wildfire mitigation planning and their potential adverse impact on risk mitigation goals. Studies in other fire-prone regions suggest that these scale mismatches are widespread and contribute to continued wildfire dwelling losses. We discuss how risk perceptions and behavior contribute to scale mismatches and how they can be minimized through integrated analyses of landscape wildfire transmission and social factors that describe the potential for collaboration among landowners and land management agencies. These concepts are then used to outline an integrated socioecological planning framework to identify optimal strategies for local community risk mitigation and improve landscape-scale prioritization of fuel management investments by government entities.
\end{abstract}

KEY WORDS: Community wildfire protection; socioecological planning; wildfire risk mitigation

\section{INTRODUCTION}

The need for more sophisticated approaches to mitigating wildfire risk is becoming more recognized as uncharacteristically large wildfires in the western United States and elsewhere overwhelm government capacities for their control and suppression. Although fire is a natural and ecologically important

${ }^{1}$ USDA Forest Service, Pacific Northwest Research Station, Western Wildland Environmental Threat Assessment Center, Corvallis, OR, USA.

${ }^{2}$ USDA Forest Service, Pacific Northwest Research Station, Corvallis, OR, USA.

${ }^{3}$ University of Michigan, School of Natural Resources and Environment, Ann Arbor, MI, USA.

*Address correspondence to Alan A. Ager, USDA Forest Service, Pacific Northwest Research Station, Western Wildland Environmental Threat Assessment Center, 3160 NE 3rd Street, Prineville, OR 97754, USA; tel: +1(541)-969-8683; aager@fs.fed.us. process in many landscapes, these so-called mega fires ${ }^{(1)}$ are atypical in their size and severity even for the fire-adapted ecosystems in which they occur. These fires burn forests, infrastructure, and homes, create hazardous air quality conditions, disrupt plant and animal communities, and alter places of scenic, ecological, and amenity value. In the United States, over 34,000 homes were destroyed by wildfire between 2003 and 2012, and suppression costs ranged from 1 to 2 billion USD per year. ${ }^{(2)}$ These fires place substantial financial burdens on federal agencies responsible for suppression and have prompted reevaluation of federal policy regarding risk management of wildfire and fire-prone forests. ${ }^{(3,4)}$

To be effective, the process of evaluating risk associated with natural hazards such as wildfire must acknowledge the influence of both biophysical and 
social factors, ${ }^{(5,6)}$ since both types of factors influence the probability and potential losses associated with an adverse event. Similarly, the process of setting mitigation priorities should consider objective evaluations of risk (i.e., based on prediction), as well as subjective evaluations of risk (i.e., based on perception) since both of these types of evaluations determine human behavior. ${ }^{(5,7-9)}$ Typically, objective (or technical) approaches to risk assessment (i.e., risk analysis) focus on statistical estimation of the probability and magnitude of adverse events, defining magnitude on the basis of economic, ecological, or social impacts. ${ }^{(5,10,11)}$ Alternative social approaches to risk assessment for mitigation planning have involved defining people's risk perceptions based on qualitative social processes such as identifying community values exposed to wildfire. ${ }^{(12-15)}$ A shortcoming of these parallel efforts is that these risk mitigation subsystems are often disconnected in planning frameworks because frameworks lack recognition of the different temporal and spatial scales at which biophysical and social processes operate (i.e., are mismatched). ${ }^{(16,17)}$ For example, in fire-prone systems, from the perspective of individuals, large wildfires are a rare event, making accurate risk perception difficult. ${ }^{(18)}$ Moreover, the risk of a large wildfire can be a function of the composition and distribution of hazardous vegetation sometimes quite distant from the location of an urban interface, ${ }^{(19,20)}$ whereas the scales on which public officials tend to plan are often the local spatial entities to which a group feels it belongs and by which a group governs itself (e.g., communities). ${ }^{(21,22)}$ These scale mismatches can inhibit simultaneous consideration of locations most likely to contribute to the creation and transmission of high levels of wildfire risk, and locations where property owners and land managers are more or less likely to contribute to landscape-level efforts to mitigate risk, both of which are necessary steps for efficiently allocating scarce risk mitigation resources in time and space. The importance of scale, feedbacks, heterogeneity, and linkages between biophysical and social systems (i.e., social ecological systems) has been emphasized in both the natural hazards and conservation planning literature. ${ }^{(6,17,23-25)}$

In this article we identify how the lack of integration between social and biophysical systems in community wildfire protection planning leads to scale mismatches that potentially compromise progress toward reducing wildfire-related losses in the wildland urban interface (WUI). We describe how existing wildfire mitigation planning can be improved using a coupled analysis of social and biophysical factors that each influence wildfire risk and mitigation opportunities. This coupled analysis leverages newer science and tools as part of a planning framework that involves assessing: (1) wildfire risk transmission networks that describe the connectivity of landscapes with respect to wildfire exposure to ecological and socioeconomic values; (2) the social potential prevalent among landowners, land managers, and communities to respond to wildfire risk through mitigation and other activities; and (3) spatially optimal strategies for prioritizing mitigation activities based on coupled analysis of biophysical and social factors that determine mitigation need and opportunity. The framework builds and improves upon current wildfire protection planning processes by explicitly linking probabilistic risk networks with social factors that drive landowner mitigation as a means to jointly consider the respective contributions to reducing potential wildfire losses. Although our article focuses on wildfire protection planning in the United States, the concepts and tools are applicable in other fire-prone regions, and potentially for mitigating other natural hazards as well.

\section{CURRENT GAPS IN WILDFIRE MITIGATION PLANNING}

Current policy in the United States focuses technical and financial assistance for wildfire mitigation on areas subject to high wildfire potential near homes, infrastructure, and other valued resources. ${ }^{(26,27)}$ By engaging in Community Wildfire Protection Planning (CWPP) processes, local stakeholder groups qualify for opportunities to influence wildfire mitigation activities on nearby federal lands and receive funding for mitigation activities on nonfederal lands (e.g., private, city, county). ${ }^{(28)}$ The planning process in the United States and elsewhere begins with the delineation of a planning boundary and an assessment of dwelling density, accessibility, fire suppression capacity, and the vegetation conditions in terms of factors that contribute to flammability and structure susceptibility. ${ }^{(29-31)}$ Plans generally propose protecting community assets in WUI areas by reducing flammable vegetation by thinning trees, creating fuel breaks between populated and wildland areas, and upgrading building construction with nonflammable materials. ${ }^{(32)}$ These planning 
guidelines are supported by research at the individual-structure level, determining characteristics that contribute to local fire risk and vulnerability to fire damage. ${ }^{(33-35)}$ The operational effectiveness of these current wildfire mitigation planning efforts can be viewed from different perspectives. Some research studies suggest that CWPPs are successful when they engage residents and other stakeholders in efforts to address mutual concerns about wildland fire management, prioritizing hazardous fuel reduction projects and improving forest health. ${ }^{(15,32)}$ Other studies, however, have found that CWPPs have not resulted in sufficient reductions of risk as large wildfires have continued to burn into WUI areas that have been treated according to CWPPs. ${ }^{(36,37)}$ Growing wildfire losses within the WUI following substantial investments in planning and mitigation would seem to indicate the existence of potential problems and unrealized expectations for risk mitigation programs. ${ }^{(2,20)}$

Despite the apparent progress in motivating both public and private sectors in fuel reduction and other risk mitigation activities, we believe that a number of key gaps exist in the current planning frameworks and prioritization process that will limit future progress toward fire-adapted communities, ${ }^{(4)}$ including: (1) inadequate biophysical characterization of risk from large fires; (2) lack of emphasis on socioeconomic drivers that influence public land managers' and private landowners' risk perceptions and their inclination and capacity to mitigate risk; and (3) incomplete integration between the assessment of the social and biophysical risk subsystems.

Regarding the first gap-inadequate biophysical characterization of risk from large fires-our assessment of typical CWPPs has revealed that few, if any, have leveraged state-of-the-science methods for characterizing wildfire risk and identifying the relevant landscape for mitigation activities. ${ }^{(38)} \mathrm{Di}$ rection in the CWPP process calls for assessing local ignition patterns and potential fire behavior, but fails to specify analytical standards and rigor for the process. ${ }^{(39)}$ In particular, current direction to delineate planning boundaries between 0.5 and 1.5 miles from a community boundary are inadequate to capture landscape-scale risk associated with large fires (e.g., 10,000-100,000 ha) that cause most of the losses within and around the WUI. These "mega fires"(1) burn through complex mosaics of fuels, topography, and land ownerships, sometimes traveling $20-50 \mathrm{~km}$ before reaching communities, ${ }^{(20)}$ and their occurrence cannot be predicted by local ignition patterns. Capturing who "owns the risk," i.e., the landowner composition of the areas that spawn large fires and the associated barriers to treating fuels, whether it be public policy or private landowner behavior, is a key analytical step omitted in the current planning process. ${ }^{(19,40,41)}$ For example, large areas of national forest are federally designated wilderness and roadless areas where mechanical fuel treatments are either prohibited or highly restricted (43\% of the area of the 82 western U.S. national forests). Similarly, land management objectives on remaining lands, such as aesthetics or habitat protection, may complicate fuel management activities in particular locations. These constraints on fuel management, intended to reduce the exposure to large fires spawned on national forests, are not quantified in current planning. Thus community protection efforts in terms of fuel management, suppression response, and homeowner activities to reduce dwelling susceptibility lack information on the collective influence of different land ownerships on the spatial and temporal heterogeneity of large fire events, and resulting risk to communities.

Regarding the second factor-lack of emphasis on socioeconomic drivers that influence risk perceptions of land managers and property owners and their inclination and capacity to mitigate risk-we note that stakeholders in current CWPP processes generally are considered equally in terms of both their perceptions and capacities to mitigate risk. This despite the body of research on human dimensions of fire that suggests substantial diversity in the awareness and perceptions of wildfire risk among people who live in fire-prone areas, as well as their inclinations and capacities to mitigate risk. ${ }^{(42-44)}$ Moreover, research studies suggest that private property owners' land management behaviors can be explained in part by variables that can be assessed and mapped locally, including, for example, ecological conditions on or near their properties, proximity to wood processing facilities, and land parcel attributes. ${ }^{(1,45-47)}$ CWPP efforts have not been systematic in their assessments of the vulnerability and capacities of diverse groups. ${ }^{(48,49)}$ Overall, these findings suggest that the lack of information about the composition of owners in a community, and the diversity in their risk perceptions and behavioral motivations in wildfire mitigation planning, is a potential shortcoming in the existing planning process that could be corrected by greater use of socioeconomic information pertaining to landowners and managers in risk mitigation planning efforts. 


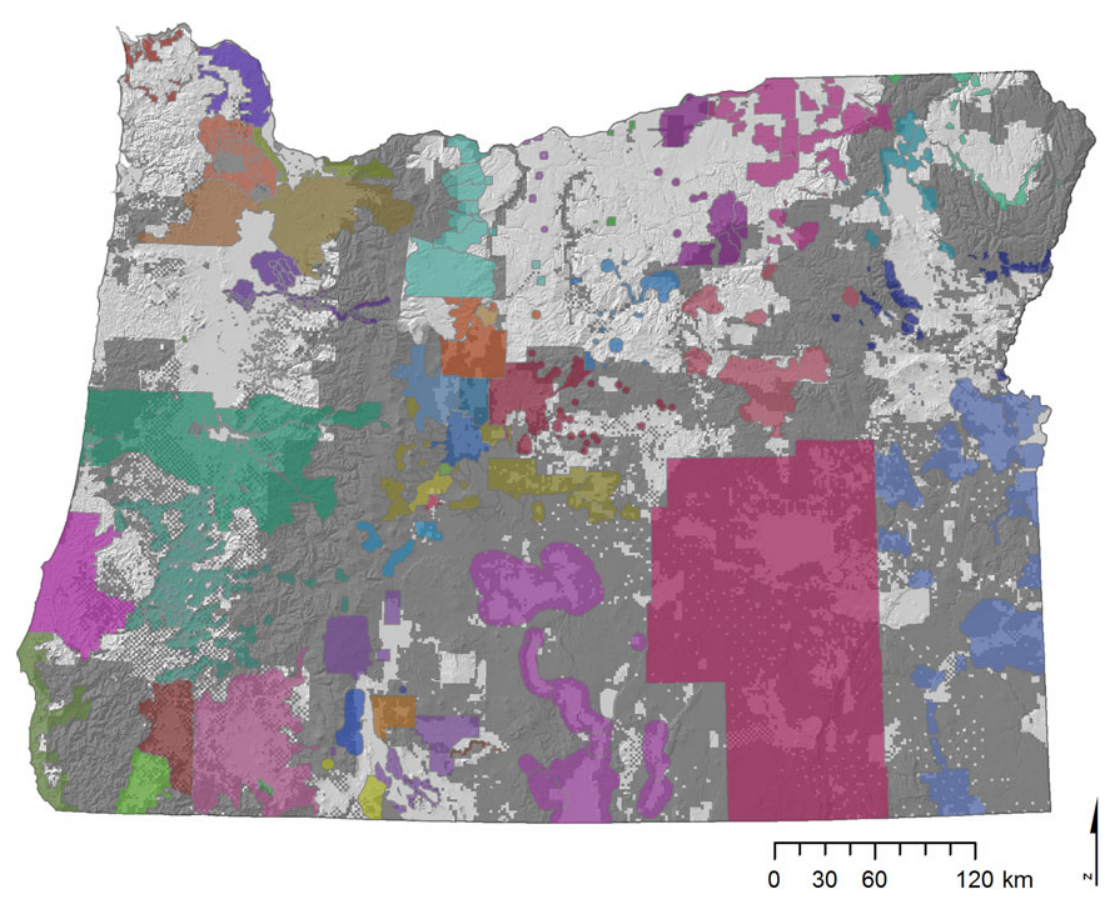

Fig. 1. Map of the state of Oregon illustrating the range of scales and delineation methods used to identify community wildfire protection plan boundaries (CWPP). Federally managed lands are shown in dark gray, and individual CWPP boundaries in different colors. The image shows that some CWPP boundaries follow natural features while others are aligned with various legal and administrative boundaries. By contrast, a biophysical delineation of planning areas would consider the scale at which wildfire events can affect communities (Fig. 3).
Regarding the third factor-incomplete integration between the assessment of the social and biophysical risk subsystems - current mitigation planning processes encourage planning on the scale of human communities, a scale that in some cases may be compatible with social processes, but not ecological processes on the large and diverse landscapes that contribute to wildfire risk. Current CWPP boundaries are generally defined by a wide range of administrative or political boundaries (e.g., fire protection districts, neighborhoods, towns, multiple towns, entire counties) that are potentially unrelated to the scale of wildfire risk transmission to communities and often to social factors relevant to risk mitigation (Fig. 1). ${ }^{(15)}$ This spatial scale mismatch between planning boundaries and the landscape scale of ecological conditions and processes has been widely discussed as a barrier to natural resource planning, particularly conservation. ${ }^{17,50-52)}$ Scale mismatches have a rippling effect through the CWPP process where: (1) property owners, land managers, and communities are potentially not aware of the sources of risk, thereby affecting risk perception and response; (2) social networks may form without key ties among landowners that share risk; (3) communities become maladapted by emphasizing wildfire response (e.g., suppression) at the expense of creating fire resilient landscapes and fire-adapted communities; ${ }^{(4)}$ and (4) the planning boundary results in a group of stakeholders in the planning process that does not include relevant landowners and public land managers. ${ }^{(53)}$ Although current flexibility in planning scale has been noted as a benefit, ${ }^{(54)}$ it exists at the expense of communities potentially failing to identify and quantify their actual sources of risk and bringing key property owners into the risk planning process, and limits integration of the assessment of the social and biophysical risk subsystems noted in other natural hazards. ${ }^{(5)}$ A similar integration gap exists at the U.S. national scale where federal investments in fuel treatments are allocated to national forests with little consideration of social factors affecting each planning region and their influence on the collective mitigation activities of all stakeholders, whether they include state and local governments, tribal entities, nongovernmental organizations, or private landowners. It is possible that this integration gap could compromise the implementation of newer federal policies with respect to the specific goal of creating fire-adapted communities. ${ }^{(4)}$

\section{NEW SCIENCE FOR WILDFIRE RISK MITIGATION PLANNING}

The analytical framework we outline here addresses the manifold effects of scale mismatches by leveraging new tools to characterize landscape 
Fig. 2. Example wildfire simulation for estimating wildfire transmission to communities. Simulated wildfire ignitions and perimeters are intersected with landowner (public, private) and wildland urban interface (WUI) boundaries to determine the potential landscape impact of specific ignition locations in terms of fire burning across landowner boundaries and into the WUI. Map is a portion of the Deschutes National Forest (DES NF) in central Oregon around the community of La Pine. The wildfire was simulated with FlamMap ${ }^{(55)}$ using fuels and weather as described in Ager et al. ${ }^{(78)}$ Hatched polygon is the outline of the 2003 Davis fire that threatened the community of La Pine.

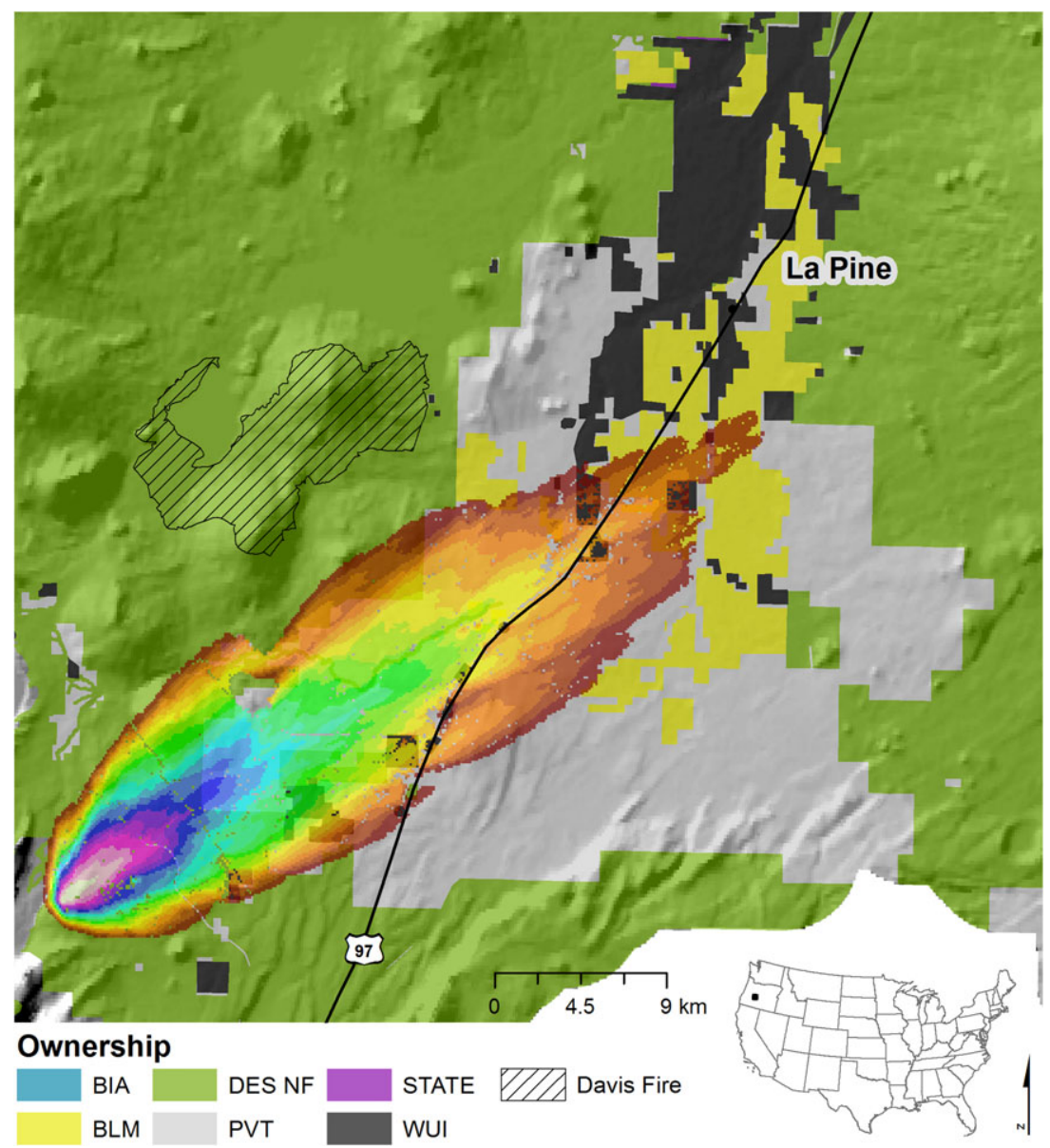

wildfire risk transmission to the WUI, and incorporates the evaluation of important social factors that influence the actions of property owners and land managers to determine optimal mitigation strategies. Recent advances in risk characterization are a key part of this framework, where efficient fire simulation algorithms ${ }^{(55,56)}$ make it possible to generate quantitative risk assessments that describe and map risk and its transmission among landowners from large wildfires. ${ }^{(57)}$ Both wildfire ignitions and their perimeters are stored for later wildfire simulations, allowing the tracking of fires as they burn through different ownerships and tabulation of different ownerships affected (Fig. 2). Summarizing many (e.g., $10^{4}$ ) fire simulations in terms of ignitions and perimeters provides a way to map wildfire transmission from national forests or other ownerships to the adjacent WUI and identify the biophysical fireshed around communities (Fig. 3). This fireshed encloses ignition locations that transmitted fire to it, thus identifying the relevant planning area from a biophysical risk standpoint for community protection planning. Transmitted risk can then be analyzed in terms of the sources of wildfire exposure and the responsible landowners, and feasibility to manage fuels (thinning, burning, fuels mastication) based on operability constraints and administrative regulations (e.g., wilderness, roadless) that prohibit mechanical fuels treatment. The net effect of using a biophysical characterization will likely be a substantial increase in the planning areas around communities (Fig. 3). This approach for delineating planning areas is in contrast to the current CWPP guidelines ${ }^{(39)}$ where boundaries are typically based on ownership and administrative borders (Fig. 1). ${ }^{(58)}$ Newer tools and simulation outputs can also be used to build risk transmission networks to characterize landscape wildfire connectivity, and network metrics can be constructed to measure and interpret patterns of wildfire risk relationships among property owners, 


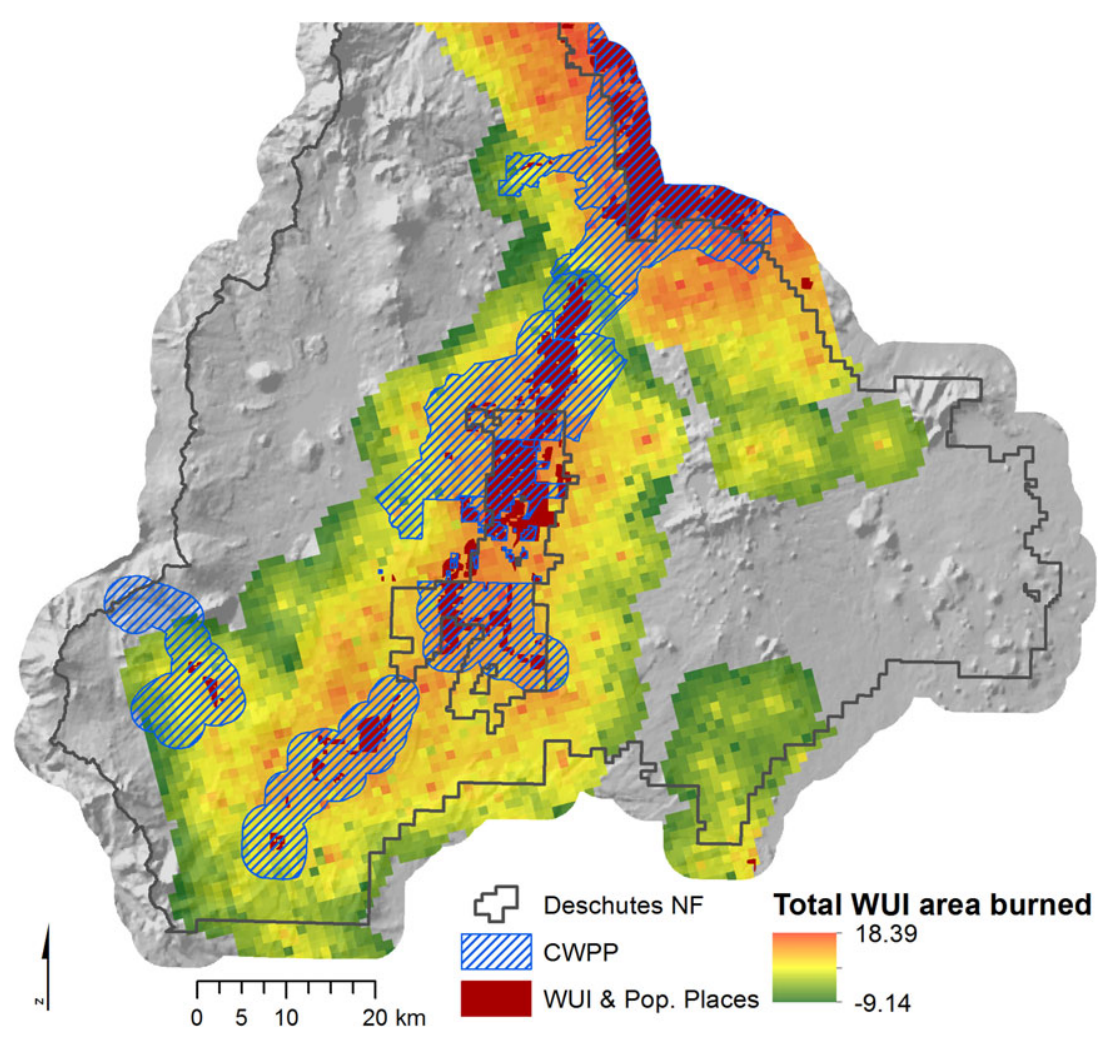

Fig. 3. Map of the southern half of the Deschutes National Forest in central Oregon showing the boundaries of: (1) community wildfire protection plans (CWPP), (2) wildland urban interface (WUI) mapped by SILVIS, ${ }^{(31)}$ and (3) the "fireshed," the area around the WUI polygons where ignitions from simulated wildfires on national forest burned into the WUI. Each ignition coordinate was attributed with the area of WUI burned by the fire associated with the ignition, and the data were then smoothed using inverse distance weighting, resulting in a "fireshed" map of areas outside the WUI that transmit fire to it. Legend shows log transformed values for total WUI area burned. Note the small size of CWPP boundaries relative to the size of the estimated fireshed. Figure adapted from Ager et al. ${ }^{(78)}$ landforms, administrative parcels, and ecological conditions (Fig. 4). Network analyses are increasingly being used as a tool in conservation biology and resource management as a way to understand landscape connectivity, ${ }^{(23,59-62)}$ and in the context of wildfire provide an analytical framework to decompose transmission on a large fragmented landscape, visualize landscape connectivity from a fire perspective, and examine the effects of fuel management (i.e., network intervention). ${ }^{(63)}$ In this way, the biophysical characterization of risk reflects the diversity of ownership patterns, wildfire connectivity among property owners, ecological conditions, and factors that constrain biophysical mitigation (fuels management). These same methods and tools can be used to test how coordinated fuel management strategies $^{(64)}$ affect wildfire transmission networks and the size and shape of community firesheds. We note that national-scale prioritization of fuel management on national forests could also take advantage of this analytical framework to direct fuel management investments in areas of high predicted wildfire transmission to WUIs.

Incorporating newer social science tools into wildfire mitigation planning also offers many avenues to improve existing mitigation efforts by property owners and land managers. Emerging social science research is demonstrating that the risk perceptions of human actors such as private property owners have been found to have a basis in actual wildfire hazardous conditions such as those measured by the potential for crown fire in the vicinity of respondents' parcels, ${ }^{(65)}$ as well as owners' past experiences with wildfire, ${ }^{(66,67)}$ among other factors. Risk perceptions in turn have been found to influence the likelihood that property owners conduct activities to mitigate wildfire risk on their properties and home sites. ${ }^{65,68)}$ Data from emerging social science research efforts can be used to develop empirical models or qualitative assessments characterizing the degree to which individual property owners are likely to engage in mitigation activities given biophysical and social circumstances in individual communities or wildfire planning areas (Fig. 5). Such models can be used to compute predicted probabilities based on prevailing landscape and socioeconomic conditions to enable public land managers and officials to identify property owners that are more or less likely to mitigate wildfire risk, and synchronize fuel management across ownerships. 
Fig. 4. (a) Map of central Oregon region showing the intermix of public and private ownerships on a fire-prone landscape. (b) Wildfire transmission network derived from simulation outputs for the same region. The nodes in the network represent landowners and the link weight represents the predicted annual fire transmitted between the nodes from simulation expressed as a percentage of the area parcel. For example, fires ignited on federal land annually burn $>10 \%$ of the Sisters urban boundary. Orange nodes indicate incorporated communities (colors visible in on-line version). IPF $=$ industrial private forest; NIPF $=$ nonindustrial private forest; WUI = wildland urban interface. (a)
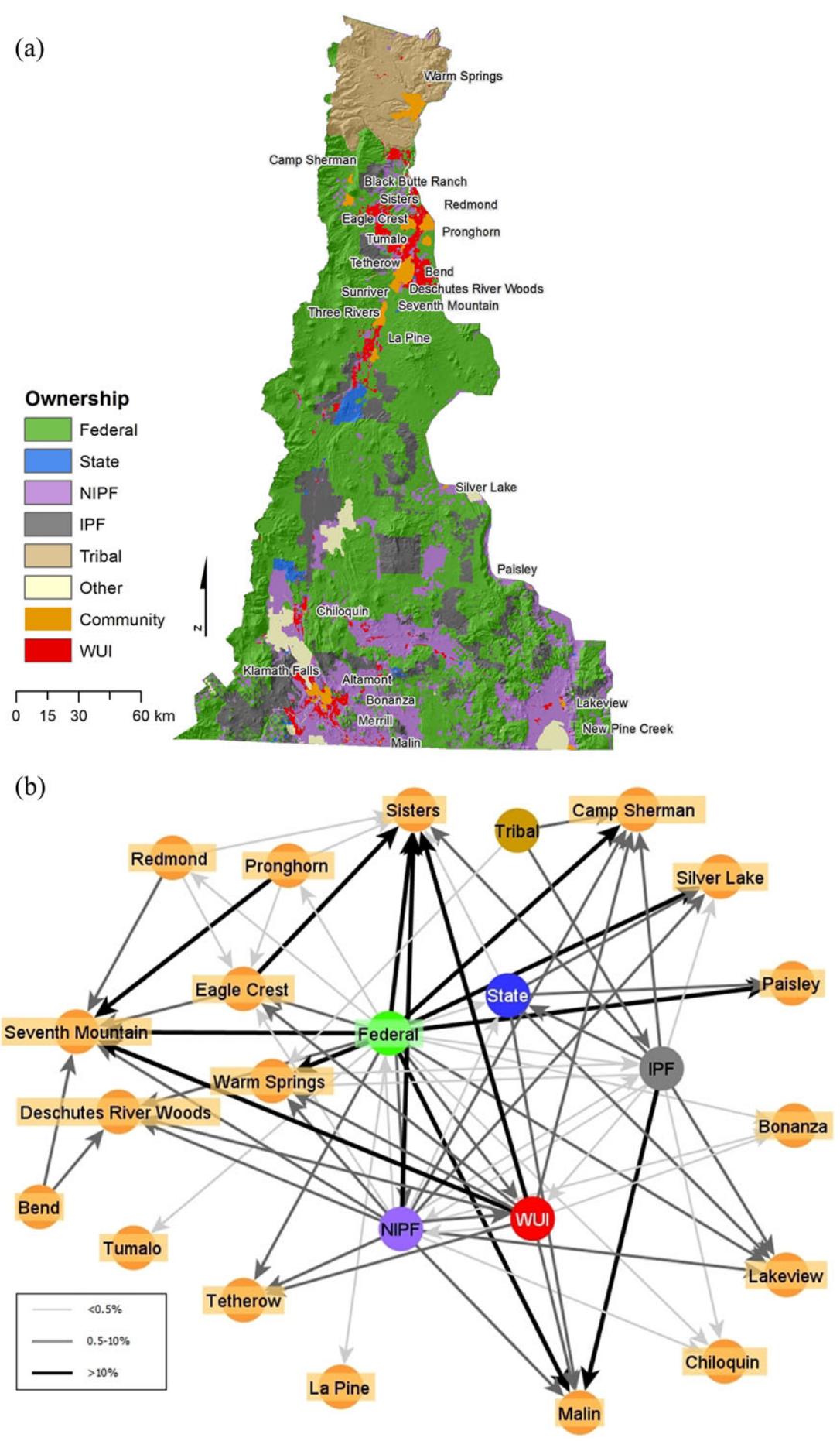

Also important are the social connections that link private property owners with neighbors, local land management agencies, and conservation and natural resource groups, and facilitate flows of information among them via social networks. ${ }^{(42,45,69,70)}$
Social networks are integral to the flows of information and resources that influence risk perceptions and capacities for mitigation behavior among both property owners and land managers. ${ }^{(65,71)}$ Since any one individual is unlikely to have direct experience 


$$
\begin{aligned}
& \operatorname{Pr}(\text { REDUCE FUEL })=\frac{\mathrm{e}^{\mathrm{x}}}{1+\mathrm{e}^{\mathrm{x}}} \\
& \begin{aligned}
\text { where } \mathrm{x}=1.414 & +\left(0.496^{*} \text { PAST FIRE }\right) \\
& +\left(0.011^{*} \text { CFL }\right) \\
& -\left(0.003^{*} \text { MILL DIST }\right)
\end{aligned}
\end{aligned}
$$

and:

PAST FIRE $=$ Dummy variable equal to one if there has been past wildfire activity on parcel; 0 otherwise.

$\mathrm{CFL}=$ Percent of $1-\mathrm{km}$ radius from parcel centroid that has passive and active crown fire potential.(19)

MILL DIST $=$ Travel distance $(\mathrm{km})$ of parcel to nearest wood processing mill using existing roads.

The probability that landowners reduce fuel is computed and mapped for the landscape based on social science data and inputs.

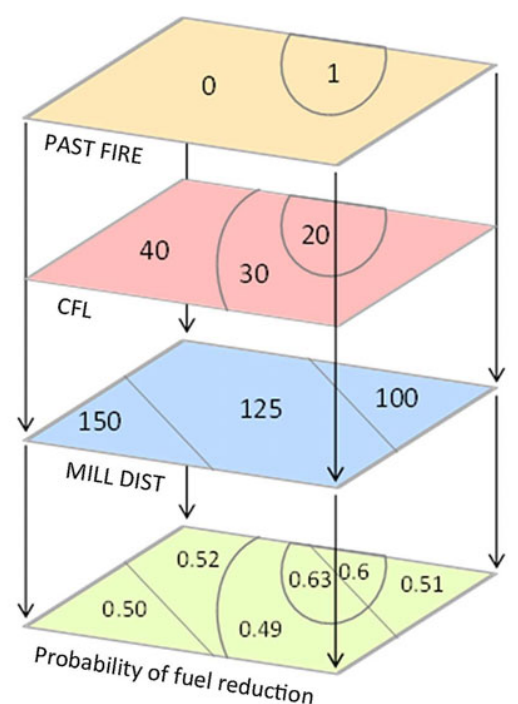

Fig. 5. Example of incorporating socioeconomic data to map the probability that landowners will engage in landscape fuel management activities. Data can be collected through formal surveys of landowners and land managers and used to build regression equations to estimate the probability that specific landowners will conduct activities that reduce fuel. ${ }^{(65)}$ The resulting map can be used in fuel management simulations to analyze the effectiveness of private risk mitigation, and reveal where fuel management of public lands is needed to synchronize mitigation efforts across public-private ownership boundaries. with a wildfire and its associated loss, these social connections potentially influence wildfire risk perceptions and mitigation activities among land managers and property owners. The role of social networks in managing wildfire risk on federal lands has become increasingly important following the establishment of external collaborative organizations with statutory authority to guide fuel management and restoration activities. ${ }^{(71-74)}$

Finally, research on socioecological networks $^{(17,23,59,60,75,76)}$ has generated new concepts and approaches for integrating information about the connectivity among human agents (i.e., landowners, land managers, organizations) and biophysical agents (e.g., landowner parcels) with implications for natural hazard and conservation planning. New approaches have been developed for linking social structures and dynamics directly into the ecological network analysis. ${ }^{(77)}$ One relevant finding here is that social connectivity viewed within the context of biophysical processes can reveal differences in scale and pattern that have implications for natural resource planning, and perhaps wildfire risk as well. For instance, the inclusion of social network data can change the priorities in conservation planning, ${ }^{(23)}$ and thus it is plausible that social-wildfire networks can reveal mitigation opportunities that are not evident from individual analyses of the separate systems. ${ }^{(23)}$ For instance, comparing wildfire risk (Fig. 4) and socioeconomic networks (Fig. 6) may reveal differences among communities in terms of sources of risk and their mitigation potential as indicated by the composition of the ties in the social fire network.

Whereas social network analysis uses metrics such as centrality and network density as indicators of potential success in planning environments and interventions to increase overall network density, ${ }^{(23)}$ wildfire network metrics measure the potential for risk transmission and the need for mitigation. Network methods can be integrated into planning frameworks to assess the potential impacts of different landowner activities and associated fuel management programs based on network-wide and landowner-specific metrics that influence risk transmission patterns and the social capacity to mitigate. For instance, alternative fuel management scenarios can be devised that emphasize hot spots for WUI risk transmission, ${ }^{(78)}$ and the resulting change in the size and shape of firesheds from fuel treatments can be examined in relation to landowner patterns and capacity to treat. Further work on integrating wildfire risk and social networks may lead to a process to build and analyze socioecological networks for wildfire mitigation planning at the community scale. An important tool for this process will be linking non-landowner organizations to landscape parcels ${ }^{(79,80)}$ to build ties between the respective social and biophysical networks.

\section{ELEMENTS OF A FIRESHED ASSESSMENT}

We propose a wildfire mitigation decision framework that applies these tools and methods for 
Fig. 6. Example social networks for fire organizations east of Oregon's Cascade Range for a portion of the region as the fire transmission network in Fig. 4. (a) Relationships among organizations involved with forest restoration (blue nodes) and wildfire protection (red nodes) in a landscape. Arrows indicate those organizations with which other organizations reported interacting for planning, funding, or conducting work on wildfire issues. (b) Relationships among organization groupings that manage or influence management of specific forest ownership types, i.e., federal, state, tribal, industrial private forestland (IPF), nonindustrial private forestland (NIPF), residential land in the WUI. Weighted arrows indicate the relative frequency of reported interactions for planning, paying for, or conducting work. The networks can be compared to the fire transmission network to identify scale mismatches and guide network weaving to strengthen ties among landowners that share wildfire risk. Data are from Fischer (unpublished).

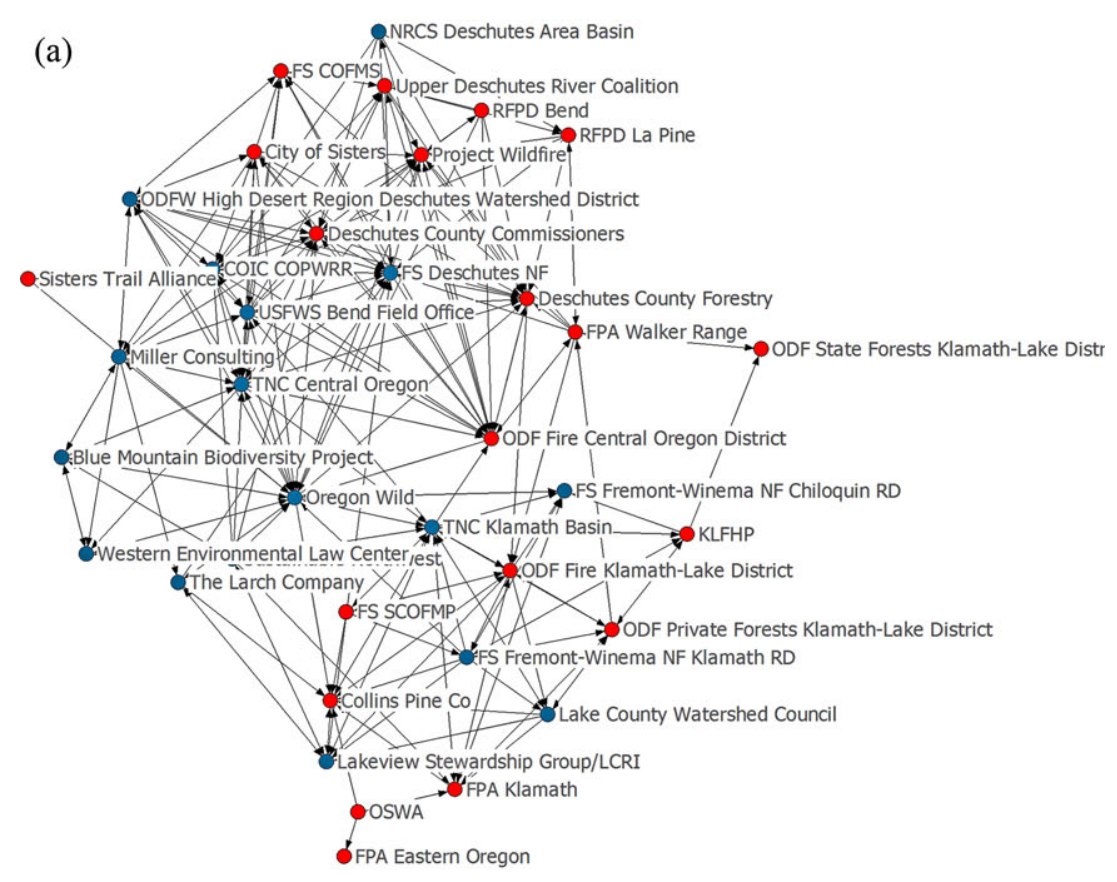

(b)

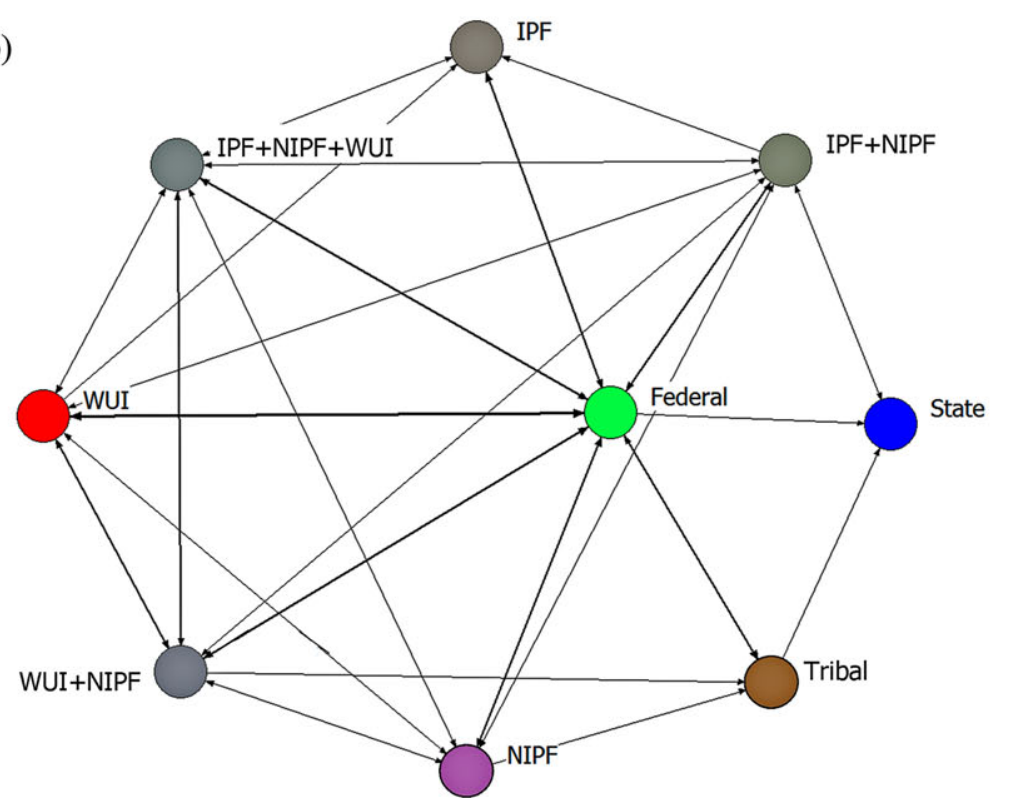

characterizing and prioritizing areas for mitigation of wildfire risk based on coupled spatial analysis of biophysical and social risk factors. This decision framework is founded on the recognition that interdependencies between biophysical and social systems engender wildfire risk, ${ }^{(81)}$ such that (1) biophysical conditions resulting from ecosystem processes and human interventions shape wildfire hazard; (2) human actors such as private property owners, public land managers, and various agencies and organizations observe and interpret wildfire hazard through the lens of cultural beliefs and norms about what constitutes risk; (3) human actors make management decisions on the basis of individual risk perceptions, as well as social constructions of risk formed through social networks; and (4) management actions influence the biophysical conditions of the landscape. The analytical elements of this framework 
leverage both the biophysical and socioeconomic sciences to augment and improve existing wildfire mitigation planning. We suggest that implementing the process would involve four interdependent analytical steps: (1) characterizing wildfire exposure from large fires and mapping firesheds to define the biophysical risk container around communities; (2) wildfire network analysis to identify risk transmission and constraints on mitigating transmitted risk to private lands; (3) assessing and mapping the social potential to mitigate in relation to fire transmission patterns; and (4) identifying optimal risk management options, including strategies to improve social fire networks and community capacity, fuel management to reduce risk transmission, and enhanced suppression response where necessary.

\subsection{Characterizing Large Fire Exposure and Mapping Firesheds}

Wildfire simulation and risk modeling for landscape planning are widely applied in the USDA Forest Service and other land management agencies to quantitatively characterize risk and exposure. ${ }^{(56)}$ They have not, however, been widely applied in CWPP projects. Protocols for wildfire modeling are well developed in terms of proper calibration and validation, ${ }^{(82,83)}$ as are practical guides for using the models in a planning environment. ${ }^{(84)}$ Methods for characterizing wildfire exposure and risk ${ }^{(57,85)}$ and mapping firesheds based on fire ignition points and perimeters to map community firesheds ${ }^{(40)}$ are well developed tools and analytical processes. These tools can also be used to analyze mitigation options such as the effect of landscape fuel treatment scenarios on fireshed size and landowner composition.

\subsection{Wildfire Network Analysis}

Outputs from the wildfire simulation methods above can be processed by network programs ${ }^{(86)}$ to visualize the transmission of fire and generate statistics on node degree, centrality, and other network metrics to describe the connectivity of the landscape. The simulation outputs can be used to partition exposure according to the management capability of the fire source, and determine, for instance, if wilderness and other amenity values on federal lands limit mitigation options. These newer methods potentially provide analytical rigor to the biophysical aspects of the "all lands" approach to risk mitigation. ${ }^{(4)}$

\subsection{Assessment and Mapping the Social Capacity to Mitigate}

This third step is an assessment of landowners' propensities for mitigation as a function of spatially explicit information on socioeconomic and ecological variables (Fig. 5), including wildfire hazard conditions on or near parcels, probable experiences with wildfire events, proximity to processing facilities, income and land values, and building codes. An assessment of mitigation potential must include both the likelihood that homeowners reduce structure susceptibility in the home ignition zone, and the potential for reducing fuels in the surrounding wildlands to address landscape-level risk. These assessments also must identify factors that may prevent particular property owners, or land managers, from either accurately perceiving wildfire risk and transmission, or taking needed action to mitigate risk. For example, property owners may have limited awareness of risk or mitigation opportunities, or may be prohibited from engaging in mitigation activities due to the high cost and a lack of resources. ${ }^{(42,65,87)}$ Social network analyses can inform social capacity assessments by revealing the extent to which social network ties among property owners or land management organizations coincide with wildfire risk transmission patterns among ownerships. They also can shed light on whether landowners have the capacity to coordinate or leverage each other's activities to influence wildfire risk on the landscape.

Evaluating existing and future wildfire risk mitigation efforts that public officials can expect of property owners and land managers can be obtained through formal surveys. For example, Fischer et al. ${ }^{(65)}$ used a survey to identify socioeconomic and biophysical factors that were correlated with nonindustrial private forest landowners' perceptions of wildfire risk and likelihood and completion of fuel reduction activities. Factors included the degree of wildfire hazard, values at risk, past wildfire experiences, and the capacity of individuals to undertake mitigation activities. This information was used to estimate a pair of regression equations that were then used to compute the probability that various property owners facing different landscape conditions will conduct activities that reduce fuel. Mapping these probabilities based on prevailing landscape conditions allows managers to identify locations where property owners are more or less likely to mitigate wildfire risk. Such analysis can aid public officials in their selection of areas to treat fuels 
as well as identify potential locations for targeted policy and programmatic intervention to encourage greater risk mitigation effort. Alternative methods to formal analysis based on survey data include using focus groups, public meetings, or expert opinion to gather information about the likely prevalence of wildfire risk mitigation within firesheds as well consider policy and programmatic approaches to increasing effort.

\subsection{Identifying Effective Risk Mitigation Options}

Based on the foregoing analyses, optimal risk management strategies can be identified by examining the spatial nexus between wildfire risk transmission and the capacity for land managers and property owners to conduct needed mitigation activities. This comparative assessment of the social and wildfire connectivity within firesheds is a key step to identifying mitigation options. Such analysis would partition the risk within the fireshed among the major land ownerships according to management capability, and identify where wildfire risk transmission and risk mitigation potential coincide, i.e., the locations where significant opportunities exist for reducing wildfire risk. For example, simulated wildfires can be used to identify ignition locations (e.g., nonindustrial private, industrial, federal, and tribal lands) that are likely to impact communities, and to identify those property owners that are most likely to undertake mitigation activities. The coincidence of high wildfire risk transmission with low potential for mitigation would define those locations where policymakers and managers may want to target policy interventions to induce greater mitigation effort among property owners. A variety of policies and programs can be used to improve the perception of risk and/or increase the participation of property owners in mitigation activities in the home ignition zone and wildfire risk transmission network, including raising awareness about wildfire risks, or offering education and technical assistance to property owners, to name a few.

\section{IMPLEMENTATION AND FUTURE WORK}

Our proposed enhancements to existing planning and prioritization frameworks would address gaps in both local planning as well as broad-scale prioritization for allocating federal and state assistance to mitigate wildfire risk on federal lands adjacent to high-risk communities. The importance of considering the larger landscape conditions in the evaluation of community wildfire risk to WUIs has been noted in fire-prone regions outside the United States as well. ${ }^{(35)}$ Although the bulk of our discussion has focused on WUI wildfire protection, these concepts have wider application in risk and hazard science, especially with regard to the use of network analysis to understand the dynamics of risk in socioecological systems. However, the specific need to improve community wildfire protection strategies is acute, as the increasing global incidence of WUI catastrophes ${ }^{(1,2,33,36,88)}$ challenges public policymakers tasked with mitigating risk. In the United States, for example, federal investments in fuels management within WUI areas exceed 200 million USD annually, and current prioritization methods do not recognize the interdependence of biophysical risk assessments on federal lands with the socioeconomic evaluation of community capacity to invest in activities on adjacent private lands. Creating fire-adapted communities ${ }^{(72)}$ adjacent to fire-prone wildlands, whether they be large tracts of protected areas or abandoned agricultural land, requires a planning framework where fuel management and fire protection strategies are synchronized among property owners. At broad regional or national scales, our methods will facilitate cross-scale linkages and consistency, a key requirement to account for implementation constraints and opportunities. ${ }^{(89,90)}$

We acknowledge the challenge of implementing new analytical protocols within community-scale planning environments. However, increasing the analytical rigor of the current process seems warranted and feasible both within the United States and elsewhere. There is wide recognition that strong quantitative methods in social planning processes are needed to facilitate implementation and eliminate scale mismatches. ${ }^{(17)}$ Conceptual papers that describe the linkage of social and biophysical networks ${ }^{(91)}$ and new tools for spatial attribute mapping ${ }^{(80)}$ can help provide a socioecological systems approach to risk mitigation planning. We note again that wildfire simulation and risk modeling for landscape planning are increasingly being applied in the United States and elsewhere, ${ }^{(92)}$ and tools and data for risk transmission and network analysis are well developed. ${ }^{(84,86,93)}$ Methods to conduct social network analyses for wildfire mitigation using focus groups, public meetings, and expert opinion will facilitate the integration of social science tools into the planning process. New investments in social science will help develop practical methods for 
conducting social assessments to aid wildfire risk management, and to foster the application of these methods among communities involved in planning efforts. We envision that case studies and application of the concepts presented in this article will eventually lead to a typology of firesheds that can be used to identify optimal management strategies based on relatively few variables and key drivers such as wildfire risk and transmission, land ownership mix, land-use policies, stakeholders, and adaptive capacity. For instance, Galiana-Martin et al. ${ }^{(94)} \mathrm{de}-$ veloped a typology of WUIs for the Valencia region in Spain based on the biophysical characteristics of local and landscape fuels in relation to structure density and vulnerability. By contrast, Paveglio et al. ${ }^{(44)}$ developed a community typology using social metrics that described adaptive capacity in terms of community response to fire risk. What is now needed is an integrated approach to classify large numbers of communities using both biophysical and social data to fully expose the primary risk factors and most efficient mitigation opportunities to improve community resilience to wildfire.

\section{ACKNOWLEDGMENTS}

We thank John Phipps for valuable discussions and feedback on ideas presented in the article. We also thank Michelle Day for editorial assistance and preparation of the figures. This research was funded in part by the USDA Forest Service, National Fire Plan and the National Science Foundation, Coupled Natural and Human Systems Program (NSF Grant CHH-1013296).

\section{REFERENCES}

1. Attiwill P, Binkley D. Exploring the mega-fire reality: A "Forest Ecology and Management" conference. Forest Ecology and Management, 2013;294:1-3.

2. Bailey D. National dialogue needed about WUI fires. Wildfire, 2013; September/October:6-7.

3. USDA Forest Service. National Wildfire Management Report to Congress and Cohesive Strategy. Washington, DC: USDA Forest Service, 2010.

4. USDA-USDI. The National Strategy: The Final Phase in the Development of the National Cohesive Wildland Fire Management Strategy, 2014, Available at: http// www.forestsandrangelands.gov/strategy/documents/strategy/ CSPhaseIIINationalStrategyApr2014.pdf, Acessed March 25, 2015.

5. Corotis RB, Hammel EM. Multi-attribute aspects for risk assessment of natural hazards. International Journal of Risk Assessment and Management, 2010; 14(6):437-458.

6. Fuchs S, Kuhlicke C, Meyer V. Editorial for the special issue: Vulnerability to natural hazards-The challenge of integration. Natural Hazards, 2011; 58(2):609-619.
7. Kasperson RE, Kasperson JX. The social amplification and attenuation of risk. Annals of the American Academy of Political and Social Science, Challenges in Risk Assessment and Risk Management, 1996; 545:95-105.

8. Slovic P. Trust, emotion, sex, politics, and science: Surveying the risk-assessment battlefield. Risk Analysis, 1999; 19(4):689701.

9. Lindell MK, Perry RW. The protective action decision model: Theoretical modifications and additional evidence. Risk Analysis, 2012; 32(4):616-632.

10. Brillinger DR, Preisler HK, Benoit J. Probabilistic risk assessment for wildfires. Environmetrics, 2006; 17:623-633.

11. Jones JM, Corotis RB. The regional consequences of individual natural hazard events. International Journal of Risk Assessment and Management, 2012; 16:78-111.

12. van Aalst MK, Cannon T, Burton I. Community level adaptation to climate change: The potential role of participatory community risk assessment. Global Environmental Change, 2008; 18(1):165-179.

13. Everett Y, Fuller M. Fire safe councils in the interface. Society and Natural Resources, 2011;24:319-333.

14. Moser SC, Ekstrom JA. Taking ownership of climate change: Participatory adaptation planning in two local case studies from California. Journal of Environmental Studies and Sciences, 2011; 1(1):63-74.

15. Williams DR, Jakes PJ, Burns S, Cheng AS, Nelson KC, Sturtevant V, Brummel RF, Staycock E, Souter SG. Community wildfire protection planning: The importance of framing, scale, and building sustainable capacity. Journal of Forestry, 2012; 110(8):415-420.

16. Kondolf GM, Podolak K. Space and time scales in human-landscape systems. Environmental Management, 2014; 53(1):76-87.

17. Guerrero AM, McAllister RRJ, Corcoran J, Wilson KA. Scale mismatches, conservation planning, and the value of socialnetwork analyses. Conservation Biology, 2013; 27(1):3444.

18. McCaffrey S. Thinking of wildfire as a natural hazard. Society and Natural Resources, 2004; 6(17):509-516.

19. Ager AA, Vaillant NM, Finney MA, Preisler HK. Analyzing wildfire exposure and source-sink relationships on a fire prone forest landscape. Forest Ecology and Management, 2012; 267(1):271-283.

20. Williams J. Exploring the onset of high-impact mega-fires through a forest land management prism. Forest Ecology and Management, 2013; 294:4-10.

21. Fall JJ. Planning protected areas across boundaries: New paradigms and old ghosts. Journal of Sustainable Forestry, 2003; 17:81-102.

22. Powell RB. Developing institutions to overcome governance barriers to ecoregional conservation. Pp. 53-66 in Trombulak, SC, Baldwin RF (eds). Landscape-Scale Conservation Planning. Netherlands: Springer, 2010.

23. Mills M, Álvarez-Romero JG, Vance-Borland K, Cohen P, Pressey RL, Guerrero AM, Ernston H. Linking regional planning and local action: Towards using social network analysis in systematic conservation planning. Biological Conservation, 2013; 169:6-13.

24. Renaud FG, Birkmann J, Damm M, Gallopin GC. Understanding multiple thresholds of coupled social-ecological systems exposed to natural hazards as external shocks. Natural Hazards, 2010; 55(3):749-763.

25. Spies TA, White EM, Kline JD, Fischer AP, Ager A, Bailey J, Bolte J, Koch J, Platt E, Olsen CS, Jacobs D, Shindler B, Steen-Adams MM, Hammer R. Challenges and a checklist for biodiversity conservation in fire-prone forests: Perspectives from the Pacific Northwest of USA and Southeastern Australia. Biological Conservation, 2012; 145(1):5-14. 
26. USDA-USDI. National Fire Plan. A Collaborative Approach for Reducing Wildland Fire Risks to Communities and the Environment. Washington, DC: United States Department of Agriculture-United States Department of Interior, 2001.

27. Healthy Forest Restoration Act of 2003. Public Law. 2003; 108-148.

28. National Fire Protection Association. About Firewise. Available at: http://www.firewise.org/about.aspx?sso=0, Accessed 21 January 2014.

29. Lampin-Maillet C, Jappiot M, Long M, Morge D, Ferrier JP. Mapping wildland-urban interfaces at large scales integrating housing density and vegetation aggregation for fire prevention in the South of France. Journal of Environmental Management, 2010; 91:732-741.

30. Lampin-Maillet C, Jappiot M, Long M, Morge D, Ferrier JP. Characterization and mapping of dwelling types for forest fire prevention. Computers, Environment, and Urban Systems, 2009; 33:224-232.

31. Radeloff VC, Hammer RB, Stewart SI, Fried JS, Holcomb SS, McKeefry JF. The wildland-urban interface in the United States. Ecological Applications, 2005; 15:799-805.

32. Jakes PJ, Nelson KC, Enzler SA, Burns S, Cheng AS, Sturtevant V, Williams DR, Bujak A, Brummel RF, GrayzeckSouter S, Staychock E. Community wildfire protection planning: Is the Healthy Forests Restoration Act's vagueness genius? International Journal of Wildland Fire, 2011; 20(3):350-363.

33. Cohen J. The wildland-urban interface fire problem. Fremontia, 2010; 38:16-20.

34. Cohen JD. Preventing disaster: Home ignitability in the wildland-urban interface. Journal of Forestry, 2000; 98(3):1521.

35. Caballero D. Wildland-urban interface fire risk management: WARM project. In González-Cabán (ed). Proceeding of the Second International Symposium on Fire Economics, Planning and Policy: A Global View. Albany, CA: USDA Forest Service, Pacific Southwest Research Station, 2004.

36. Graham R, Finney M, McHugh C, Cohen J, Calkin D, Stratton R, Bradshaw L, Nikolov N. Fourmile Canyon Fire Findings. Fort Collins, CO: USDA, Forest Service, Rocky Mountain Research Station Report No.: RMRS-GTR-289, 2012.

37. Fleeger WE, Becker ML. Decision processes for multijurisdictional planning and management: Community wildfire protection planning in Oregon. Society \& Natural Resources, 2010; 23(4):351-365.

38. Miller C, Ager AA. A review of recent advances in risk analysis for wildfire management. International Journal of Wildland Fire, 2012; 22(1):1-14.

39. CWPP Task Force. Community Guide to Preparing and Implementing a Community Wildfire Protection Plan 2008. Available at: http://www.forestsandrangelands.gov/communities/documents/CWPP_Report_Aug2008.pdf, Accessed 21 January 2014.

40. Ager AA, Day MA, Finney MA, Vance-Borland K, Vaillant NM. Analyzing the transmission of wildfire exposure on a fireprone landscape in Oregon, USA. Forest Ecology and Management, 2014; 334:337-390.

41. Ager AA, Finney MA, Vaillant NM. Analyzing the spatial transmission of wildfire risk from large fires. Pp. 108-113 in Spano D, Bacciu V, Salis M, et al. (eds). Modelling Fire Behaviour and Risk. Alghero, Italy: Nuova StampColor, 2012.

42. Fischer AP, Charnley S. Risk and cooperation: Managing hazardous fuel in mixed ownership landscapes. Environmental Management, 2012; 49(6):1192-1207.

43. Paveglio T, Jakes P, Carroll M, Williams D. Understanding social complexity within the wildland-urban interface: A new species of human habitation? Environmental Management, 2009; 43(6):1085-1095.
44. Paveglio T, Moseley C, Matthew MSC, Williams Dr, Davis EJ, Fischer AR. Categorizing the social context of the wildland urban interface: Adaptive capacity for wildfire and community "archetypes," Forest Science, 2015: 60.

45. Fischer AP, Kline JD, Ager AA, Charnley S, Olsen KA. Objective and perceived wildfire risk and its influence on private forest landowners' fuel reduction activities in Oregon's (USA) ponderosa pine ecoregion. International Journal of Wildland Fire, 2014; 23(1):143-153.

46. Lynch L, Lovell SJ. Combining spatial and survey data to explain participation in agricultural land reservation programs. Land Economics, 2003; 79(2):259-276.

47. Pocewicz A, Nielsen-Pincus M, Goldberg C, Johnson M, Morgan P, Force J, Waits L, Vierling L. Predicting land use change: Comparison of models based on landowner surveys and historical land cover trends. Landscape Ecology, 2008; 23(2):195210.

48. Gaither CJ, Poudyal NC, Goodrick S, Bowker JM, Malone S, Gan J. Wildland fire risk and social vulnerability in the southeastern United States: An exploratory spatial data analysis approach. Forest Policy and Economics, 2011; 13(1):24-36.

49. Ojerio R, Moseley C, Lynn K, Bania N. Limited involvement of socially vulnerable populations in federal programs to mitigate wildfire risk in Arizona. Natural Hazards Review, 2011; 12(1):28-36.

50. Cumming GS, Cumming DHM, Redman CL. Scale mismatches in social-ecological systems: Causes, consequences, and solutions. Ecology and Society, 2006; 11(1):14.

51. Landres PB, Knight RL, Pickett STA, Cadenasso ML. Ecological effects of administrative boundaries. Pp. 39-64 in Knight RL, Landres PB (eds). Stewardship Across Boundaries. Washington, DC: Island Press, 1998.

52. Sarkar S, Pressey RL, Faith DP, Margules CR, Fuller T, Stoms DM, Moffett A, Wilson KA, Williams KJ, Williams PH, Andelman S. Biodiversity conservation planning tools: Present status and challenges for the future. Annual Review of Environment and Resources, 2006; 31:123-159.

53. Cheng AS, Daniels SE. Examining the interaction between geographic scale and ways of knowing in ecosystem management: A case study of place-based collaborative planning. Forest Science, 2003; 49(6):841-854.

54. Jakes P, Burns S, Cheng A, Saeli E, Nelson K, Brummel R, Grayzeck S, Sturtevant V, Williams D. Critical elements in the development and implementation of community wildfire protection plans (CWPPs). In Butler BW, Cook W (eds). The Fire Environment-Innovations, Management and Policy; Conference Proceedings. Fort Collins, CO: USDA Forest Service, Rocky Mountain Research Station, 2007.

55. Finney MA. An overview of FlamMap fire modeling capabilities. Pp. 213-220 in Andrews PL, Butler BW (eds). Fuels Management-How to Measure Success: Conference Proceedings. Proceedings RMRS-P-41, March 28-30, 2006. Fort Collins, CO: USDA Forest Service, Rocky Mountain Research Station; 2006.

56. Finney MA, McHugh CW, Grenfell IC, Riley KL, Short KC. A simulation of probabilistic wildfire risk components for the continental United States. Stochastic Environmental Research and Risk Assessment, 2011; 25:973-1000.

57. Ager AA, Day MA, McHugh CW, Short K, Gilbertson-Day J, Finney MA, Calkin DE. Wildfire exposure and fuel management on western US national forests. Journal of Environmental Management, 2014; 145:54-70.

58. Jakes PJ, Nelson KC, Enzler SA, Burns S, Cheng AS, Sturtevant V, Williams DR, Bujak A, Brummel RF, GrayzeckSouter S, Staychock E. Community wildfire protection planning: Is the Healthy Forests Restoration Act's vagueness genius? International Journal of Wildland Fire, 2011; 20:350363. 
59. Minor ES, Urban DL. A graph-theory framework for evaluating landscape connectivity and conservation planning. Conservation Biology, 2008; 22:297-307.

60. Kininmonth S, Berger M, Bode M, Peterson E, Adams VM, Dorfman D, Brumbaugh DR, Possingham HP. Dispersal connectivity and reserve selection for marine conservation. Ecological Modelling, 2011; 222:1272-1282.

61. Rayfield B, Fortin MJ, Fall A. Connectivity for conservation: A framework to classify network measures. Ecology, 2011; 92(4):847-858.

62. Foltête JC, Giradet X, Clauzel C. A methodological framework for the use of landscape graphs in land-use planning. Landscape and Urban Planning, 2014; 124:140-150.

63. Valente TW. Network interventions. Science, 2012; 337:49-53.

64. Collins BM, Stephens SL, Moghaddas JJ, Battles J. Challenges and approaches in planning fuel treatments across fire-excluded forested landscapes. Journal of Forestry, 2010; 108:24-31.

65. Fischer AP, Kline JD, Ager AA, Charnley S, Olsen KA. Objective and perceived wildfire risk and its influence on private forest landowners' fuel reduction activities in Oregon's (USA) ponderosa pine ecoregion. International Journal of Wildland Fire, 2014; 23:143-153.

66. Cohn PJ, Williams DR, Carroll MS. Wildland-urban interface residents' views on risk and attribution. Pp. 23-43 in Martin, WE, Raish C, Kent B (eds). Wildfire Risk: Human Perceptions and Management Implications. Washington, DC: Resources for the Future. 2008.

67. Gordon JS, Luloff A, Stedman RC. A multisite qualitative comparison of community wildfire risk perceptions. Journal of Forestry, 2012; 110(2):74-78.

68. Champ PA, Donovan GH, Barth CM. Living in a tinderbox: Wildfire risk perceptions and mitigating behaviours. International Journal of Wildland Fire, 2013; 22(6):832-840.

69. Brenkert-Smith H. Building bridges to fight fire: The role of informal social interactions in six Colorado wildland-urban interface communities. International Journal of Wildland Fire, 2010; 19(6):689-697.

70. Brenkert-Smith H, Dickinson KL, Champ PA, Flores N. Social amplification of wildfire risk: The role of social interactions and information sources. Risk Analysis, 2013; 33(5):800817.

71. Butler WH, Goldstein BE. The US Fire Learning Network: Springing a rigidity trap through multiscalar collaborative networks. Ecology and Society, 2010; 15(3):21.

72. USDA-USDI. National Cohesive Wildland Fire Management Strategy 2015. Available at: http://www.forest sandrangelands.gov/strategy/index.shtml, Accessed March 25, 2015.

73. Goldstein BE, Butler WH. The U.S. Fire Learning Network: Providing a narrative framework for restoring ecosystems, professions, and institutions. Society \& Natural Resources, 2010; 23(10):935-951.

74. Wildland Fire Leadership Council. A National Cohesive Wildland Fire Management Strategy: Western Regional Assessment and Strategy. Wildland Fire Leadership Council, 2011. Available at: http://www.forestsandrangelands.gov/ leadership/documents/wfec/meetings/04nov2011/regreports_ presentations/phase2_report_wrsc20110930.pdf, Accessed March 25, 2015.

75. Bascompte J. Disentangling the web of life. Science, 2009; 325:416-419.

76. Cumming GS, Bodin Ö, Ernstson H, Elmqvist T. Network analysis in conservation biogeography: Challenges and opportunities. Diversity and Distributions, 2010; 16:414-425.
77. Bodin O, Crona B, Ernstson H. Social networks in natural resource management: What is there to learn from a structural perspective? Ecology and Society, 2006; 11(2):r2.

78. Ager AA, Day MA, Finney MA, Vance-Borland K, Vaillant NM. Analyzing the transmission of wildfire exposure on a fireprone landscape in Oregon, USA. Forest Ecology and Management, 2014; 334:337-390.

79. Brown G. Mapping spatial attributes in survey research for natural resource management: Methods and applications. Society and Natural Resources, 2005; 18(1):17-39.

80. Nielsen-Pincus M. Mapping a values typology in three counties of the interior Northwest, USA: Scale, geographic associations among values, and the use of intensity weights. Society and Natural Resources, 2011; 24(6):535-552.

81. Spies TA, White EM, Kline JD, Fischer AP, Ager A, Bailey J, Bolte J, Koch J, Platt E, Olsen CS, Jacobs D, Shindler B, Steen-Adams MM, Hammer R. Examining fire-prone forest landscapes as coupled human and natural systems. Ecology and Society, 2014; 19(3):9.

82. McHugh CW. Considerations in the use of models available for fuel treatment analysis. Pp. 81-105 in Andrews PL, Butler BW (eds). Fuels Management-How to Measure Success. Proceedings RMRS-P-41, 28-30 March 2006. Fort Collins, CO: USDA Forest Service, Rocky Mountain Research Station, 2006.

83. Stratton RD. Guidance on Spatial Wildland Fire Analysis: Models, Tools, and Techniques. Fort Collins, CO: USDA Forest Service, Rocky Mountain Research Station Report No.: RMRS-GTR-183, 2006.

84. Ager AA, Vaillant NM, Finney MA. Integrating fire behavior models and geospatial analysis for wildland fire risk assessment and fuel management planning. Journal of Combustion, 2011; Article ID 572452:19.

85. SRA. Society for Risk Analysis. 2006. Available at: http://www.sra.org/, Accessed November 26, 2013.

86. Borgatti SP, Everett MG, Johnson JC. Analyzing Social Networks. Thousand Oaks, CA: Sage Publications, 2013.

87. Fischer AP. Reducing hazardous fuels on nonindustrial private forests: Factors influencing landowner decisions. Journal of Forestry, 2011; 109(5):260-266.

88. Cruz MG, Sullivan AL, Gould JS, Sims NC, Bannister AJ, Hollis JJ, Hurley RJ. Anatomy of a catastrophic wildfire: The Black Saturday Kilmore East Fire in Victoria, Australia. Forest Ecology and Management, 2012; 284:269-285.

89. Pierce SM, Cowling RM, Knight AT, Lombard AT, Rouget M, Wolf T. Systematic conservation planning products for land-use planning: Interpretation for implementation. Biological Conservation, 2005; 125(4):441-458.

90. Knight AT, Cowling RM, Rouget M, Balmford A, Lombard AT, Campbell BM. Knowing but not doing: Selecting priority conservation areas and the research-implementation gap. Conservation Biology, 2008; 22:610-617.

91. Bodin Ö, Tengö M. Disentangling intangible social-ecological systems. Global Environmental Change, 2012; 22:430-439.

92. Salis M, Ager A, Arca B, Finney MA, Bacciu V, Duce P, Spano D. Assessing exposure of human and ecological values to wildfire in Sardinia, Italy. International Journal of Wildland Fire, 2012; 22(4):549-565.

93. Brandes U, Wagner D. Analysis and visualization of social networks. Pp. 321-340 in Jünger M, Mutzel P (eds). Graph Drawing Software. Berlin: Springer, 2004.

94. Galiana-Martin L, Herrero G, Solana J. A wildland-urban interface typology for forest fire risk management in Mediterranean areas. Landscape Research, 2011; 36(2):151171. 